\title{
Identification and analysis of risks with major involvement in the staff activity of tourist pension
}

\author{
Maria Georgiana MOCANU ${ }^{1}$, and Dorina MOCUTA ${ }^{2,1 *}$ \\ 1University of Agronomic Sciences and Veterinary Medicine of Bucharest, 59 Marasti Blvd., District \\ 1, Bucharest, Romania \\ 2University of Agronomic Sciences and Veterinary Medicine of Bucharest, 59 Marasti Blvd., District \\ 1, Bucharest, Romania
}

\begin{abstract}
The human factor is the indispensable resource of tourist pensions due to which the activity of this sector is achievable, but inadequate training leads to many risks for all parties involved, namely employees, employer, but also consumers, suppliers and other parties.For a healthy development, the society must go through all the established stages so that the frequency of the risks that may appear to be reduced to almost nullity. Particular importance must be given in the risk management process so that they are identified and controlled in a relatively short time so as not to face undesirable results.
\end{abstract}

Research background: At the level of tourist pensions, we face a series of risks that must be identified in due time.

Purpose of the article: Identify the main risks that may occur.

Methods: The identification of risks is made on the basis of a very well established analysis by persons accredited in this field.

Findings \& Value added: In order to establish the risks that may arise, it is desired to determine a very efficient method that can be applied at the level of society and which aims at the human resources part and their preparation.

Keywords: human resource, risk, identification, control, results.

1* Corresponding author: dorinamocuta@yahoo.com 


\section{INTRODUCTION}

Globally, the most dynamic sector of activity is reflected in the tourism industry, because in addition to this sector that generates many jobs, there is also a particularly important sector that generates an economic recovery for countries where the tourist potential is properly exploited.

Tourism from the perspective of entrepreneurs is an important source of investment that can bring a significant gain, and seen from the perspective of consumers is that activity that revitalizes you and brings you emotional and cultural satisfaction and recharges your soul with positive energy.

Depending on the purpose of the trip, there is a functional classification of tourism modes:

- Cultural tourism

- Leisure tourism

- Balneary tourism

- Business tourism

- Ecumenical tourism

- Ethnic tourism

- Ecotourism

- Rural tourism

- Adventure tourism

- Sports tourism

- Tourism in transit.

Human resources are a vital element for a business to be born, survive and grow beautifully. The quality of the human factor is very important to create the new resources that society needs to survive. No matter what you want to synthesize, man has been the main driver of a business since its inception. Nasbitt and Aburdene stated that "in the new information society, human capital has replaced financial capital as a strategic resource" [2].

Risk is an event that must be assumed in any field of activity and not only. Human psychology is created so that it can survive permanently with certain feelings that are uncertain, being ready to act and solve possible situations that may occur at every step.

There are specialists in the area who ask questions for which they do not have encouraging answers when it comes to eliminating and replacing human resources, eg: "What is an organization without its employees? There is nothing in the absence of human resources, possibly a lot of expensive equipment" [3].

The whole cycle of a society starts from the idea that a person nourishes the subconscious, it gets to translate it into ideas, then comes to life, and to grow there is a need for labor and easily human resources are indispensable to the "life" of a companies.

In order to create a solid organization, there must be a superior management process.

The management process is composed of four major components: $\mathrm{P}-\mathrm{O}-\mathrm{L}-\mathrm{C}$, respectively planning, organization, leadership and control.

Planning consists in determining the objectives to be achieved and the way in which they are to be achieved.

Organizing by establishing an organizational structure and allocating the necessary resources so that the goal is achieved. 
Leadership through open communication and motivation so that the goal is common to all parties involved.

Control by establishing a control system for monitoring and evaluating the results obtained compared to those planned and taking measures to achieve the desired result by correcting errors.
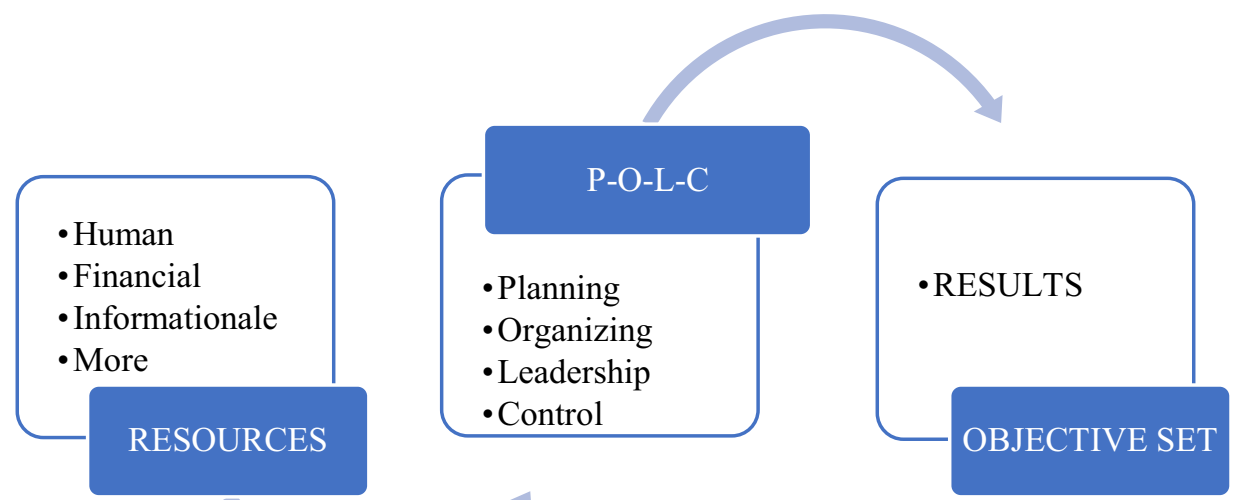

Fig. no 1. Mode of operation of the senior management process

The risk is an unsafe and uncertain event that can cause many damages. The definition of risk is set out in several ways depending on how it looks:

$\checkmark$ "The risk can be defined as the possibility that the losses will be higher than expected."[4]

$\checkmark \quad$ "The risk is the uncertainty about the damage."[5]

Starting from the idea that any activity involves risks that come in different forms, we will analyze the main risks within the human resources department in the area of tourism, starting from the motto of the well-known literary critic Eugen Lovinescu, respectively "When you start an action, you have to consider its risks as well".

\section{MATERIALS AND METHODS}

The risk in the tourism activity can be viewed both from an economic point of view, taking into account the financial damage that the company may face, but also from a social point of view that is generated by the collectivity of a company. The actions taken by the community can cause risks that can have major effects on the entire business. We can describe a series of risks that the company may face [7-9]:

- Financial risk - is the most common because any event with a positive or negative result is reflected in the financial situation.

- Information risk - not enough is invested in the technological part and information leaks can occur, even involving key elements for bank accounts or other valuable elements of the company.

- Natural risks - which are the most unpredictable and uncontrollable risks because their production is based on a multitude of factors difficult to control.

But these categories of risks can be extended on several levels depending on the company's activity and the range of activities to be carried out: 
○ Physical risks (eg: fatigue, working at height, working indoors, etc.);

- Chemical risks (eg use of toxic products);

- Biological risks (eg infection with various viruses; bacteria);

○ Psychological risks (eg stress, tiredness);

- Mechanical risks (eg: equipment management);

○ Electrical risks (eg electronic equipment management) etc.

The risks are determined according to the company's activity and the processes involved in its development. For this reason, it is recommended for companies that the risk management be of the best quality, so that the chances of a guaranteed fail must be as low as possible by correctly identifying and understanding the risk and by analyzing in the smallest detail the control methods and minimizing its production.

The definition of risk is perceived as a phenomenon with negative consequences, but for those who truly understand this term, risk can also have positive consequences.

The risk management process is embedded in a continuous cycle that takes place as follows:

1. Setting objectives;

2. Risk identification - threats and vulnerabilities that society faces;

3. Analysis and evaluation of risks - what are the determined risks and what is the probability of their occurrence;

4. Risk management - solutions to reduce the possibility of occurrence;

5. Transposing risks by managing the necessary measures to be implemented in risk management.

How can we determine the probability of a risk? Through a very well structured and studied risk management, taking into account all the variables that can represent an important element in its production, respectively the reduction of the chances of risk production.

Within the tourist pensions and not only must be considered the improvement of the activity of prevention and reduction of work accidents, occupational diseases, activities that can be optimized by real assessment of the risks that have as final result the occurrence of an accident or occupational disease.

Accidents at work can be defined as the action of factors that can result in injury to the human factor, the creation of physiological dysfunctions, various diseases of the body.

In principle, most countries limit the number of diseases that are considered to be occupational diseases, for example [12-13]:

- inhalation poisoning;

- $\quad$ epidemic contact with certain toxic substances;

- diseases of exposure to cold / heat / noise / vibration / high or low atmospheric pressure;

- occupational allergies / dermatoses;

- occupational cancer;

- other diseases.

In Romania, the part of work accidents is regulated based on Law 319/2006, updated in 2020. We must start from the identification of risk factors and it must be borne in mind that any dysfunction of the factors involved in the work process originates outside the process itself and even before the start of the company's activity (the design of the business itself).

For the launch of the project itself, there must be a vision as broad as possible or during the conception, projection and execution to be taken into account and the inconsistencies that may generate various risks. 
The risks that are based on the human factor as the main element in tourist pensions must perform and balance the objectives to be achieved and the resources we have to achieve our purposes.

In a risk identification mission we start from the duties of the job, check the tools used and how they are used. If they are used according to the tools then the risks they identify are minimal, but in most cases either there are no necessary tools or the tools provided to the employee are not used according to the training.

Given the current situation regarding staff turnover as well as the difficulty of recruiting new staff in vacancies, the company is facing the need for urgent employment without having to go through the recruitment cycle. Within the tourist pensions, most of the identified risks are due to the lack of attention or lack of knowledge regarding the recruitment of employees, but also the professional training they need to learn the necessary skills.

Even if most entrepreneurs consider that the recruitment process is not important, if it were done in optimal conditions, the risks that may arise in society would be significantly reduced.

The main mistakes made in the recruitment process are [16-18]:

1. Approaching external recruitment, without taking into account the possibility of recruiting existing staff to a vacant post by retraining. If an internal recruitment were taken into account, it has a number of benefits because it is even more efficient and leads to increased staff retention at company level.

2. The incorrect analysis of the need for recruitment, happens in the busier periods without taking into account another way of distributing the activity considering that the activity does not need other people.

3. Rigid rectification criteria established at company level. In the recruitment process it is one of the elements where employers often make mistakes because they want a perfect person who knows how to do everything, without taking into account and defining the main duties of the job for which the recruitment is done.

4.Testing candidates by assigning questions or requesting a contact to request recommendations. Which is not the case because this process is often treated superficially.

5. Comparison of candidates either with the employee who held the position for which they are recruited, or a comparison with other candidates, which is not a favorable criterion for the employer because each person is different, and the comparison when there is no unitary criterion is not the most correct.

6. Excessive prolongation of the recruitment process, it must be taken into account that the response time is not too long to keep the ideal candidate, but often the hiring is done for a person other than the one selected later due to the waiting time.

There are many mistakes made by employers in the recruitment process and therefore the degree of risk is very high. From the selection of a candidate that is considered appropriate at the time of the recruitment process to the time when he carries out the actual activity, a strategic plan for monitoring and evaluating the employee must be developed.

In order to determine whether the chosen candidate is the right one, the employer must take into account the provision of the Labor Code regarding the probationary period, which may be up to 90 calendar days for executive positions and up to 120 calendar days for management positions.

The main risks that we can identify at the level of a tourist boarding house and which are based on human errors, respectively the absence of professional training, are: 
- Financial risks: costs incurred by the employer in certain unforeseen situations, respectively the payment of errors arising from the non-compliant performance of the activity.

- Functional risks: services provided by employees, which do not meet customer expectations.

- $\quad$ Physical risks: what involves the physical injury of both customers and employees through improper use of objects, equipment or other objects that can generate such situations.

- Psychological risks: these are identified at the level of the individual and are generated by the perception of different situations that can have a particularly serious impact on health.

- Social risks: how to relate at group-employee level; group-customers.

- Risk of non-integration: occurs constantly among staff, due to values that are different or the culture of the organization that does not provide how this process takes place.

As you can see, the risks that can be identified at the level of tourist pensions are numerous and the list does not end here because risks exist at the level of each department, each action performed at the level of society. It is very important that these risks are identified in a timely manner through risk management so that the frequency of occurrence is very low.

In practice we find many methods to determine the risk depending on the elements that are involved in this process and can be direct elements and indirect elements.

I. The basis of the risk assessment principle involves the analysis of two essential parameters [19-20]:

Frequency - probability of occurrence

$>$ Gravity - the expected loss $R=\sum$ (probability of occurrence) $x$ (expected loss in case of occurrence)

II. Another method of risk analysis that risk management experts approach is based on the systematic assessment of risks reflected in the activity of pensions:

\begin{tabular}{|c|c|c|c|c|c|c|}
\hline \multirow[t]{2}{*}{$x^{2}+x^{2}$} & & \multicolumn{5}{|c|}{ Damage vastness } \\
\hline & & $\begin{array}{l}\text { Risk of } \\
\text { personal } \\
\text { injury to } \\
\text { staff }\end{array}$ & $\begin{array}{l}\text { Risk of } \\
\text { inadequate } \\
\text { level of } \\
\text { training }\end{array}$ & $\begin{array}{l}\text { Risk of } \\
\text { negative } \\
\text { financial } \\
\text { impact }\end{array}$ & $\begin{array}{l}\text { Risk of } \\
\text { pension } \\
\text { fraud }\end{array}$ & $\begin{array}{l}\text { Risk of injury to } \\
\text { customers due to } \\
\text { professional } \\
\text { misconduct }\end{array}$ \\
\hline \multicolumn{7}{|l|}{ Probability } \\
\hline Frequent & $\mathrm{A}$ & 3 & 2 & 1 & 1 & 1 \\
\hline Occasionally & $\mathrm{B}$ & 1 & 2 & 2 & 1 & 1 \\
\hline Uncommon & $\mathrm{C}$ & 3 & 1 & 2 & 1 & 1 \\
\hline Improbable & $\mathrm{D}$ & 3 & 2 & 2 & 2 & 1 \\
\hline Almost impossible & $\mathrm{E}$ & 3 & 2 & 2 & 2 & 1 \\
\hline
\end{tabular}

\begin{tabular}{|l|l|l|}
\hline Risk level & Pontetial risk & Measures (depending on the frequency of risks) \\
\hline
\end{tabular}




\begin{tabular}{|l|l|l|}
\hline 1 & High & Rapid action to reduce the level of risk \\
\hline 2 & Middle & Short-term action to reduce the level of risk \\
\hline 3 & Low & Medium / long term action based on training \\
\hline
\end{tabular}

Fig. no. 2: Systematic risk analysis

This systematic analysis [18;21-23] is made on the basis of sheets that are completed when the risks are assessed by experts in the field, based on which a score is established by which a certain category of risk can fall into one of the levels of risk mentioned in Fig. no. 2 .

\section{RESULTS AND CONCLUSIONS}

"How can we reduce the risks?" is one of the questions that entrepreneurs frequently ask specialists when using the services designed to ensure the proper functioning of the business and its conduct under normal conditions so that the results obtained are the desired ones.

For the beginning, the established stages in the risk management process will be followed, according to figure no. 3, during which the research methodology to be applied is established. The descriptive research will be based on a well-structured questionnaire that helps us reach a result as efficient as possible.

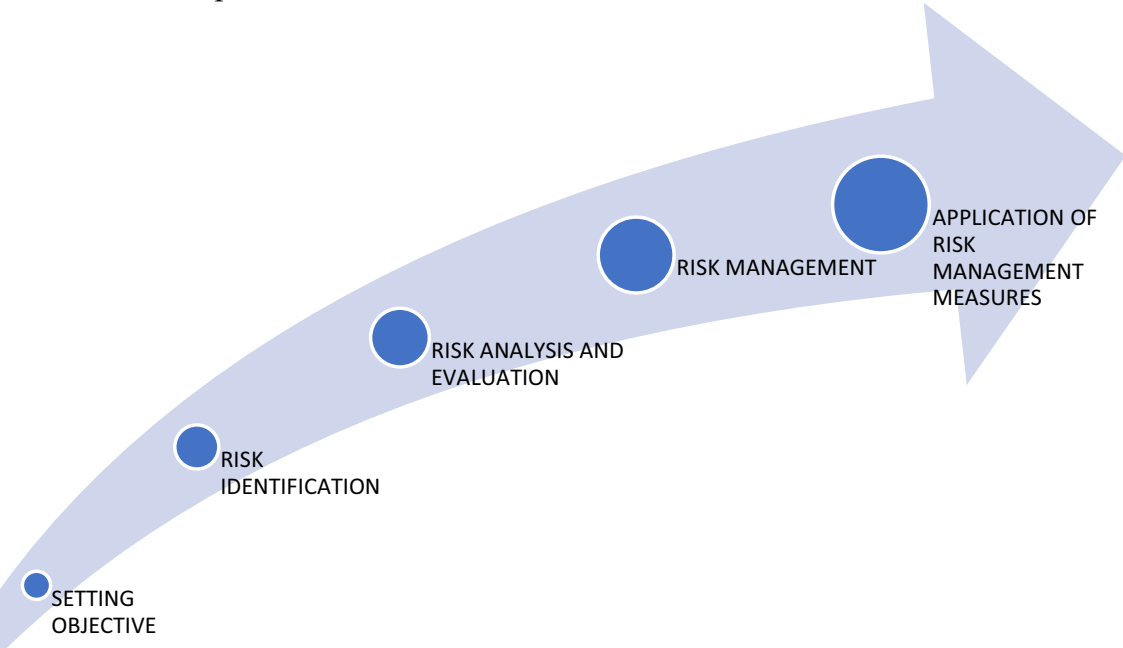

Fig. no. 3. Risk management process

In order to be able to establish what are the risks that can appear within a pension, it must be developed, reinvented and the ongoing process of change, respectively the renewal of the process, product or service it offers, must be carried out.

Innovative changes have a significant impact on key elements of the organization and 
some of them are: structure, technology, human resources and culture. In order to determine the risks that may arise and benefit from the desired success, the attitude that we show in solving these problems matters a lot.

\section{REFERENCES}

1. Cascio, W., Boudreau, J., (2014), HR strategy: optimizing risks, optimizing rewards, Journal of Organizational Effectiveness: People and Performance, Vol. 1 Issue: 1, pp.77-97.

2. Mitrofanova, A., (2013), The concept of HR risk management in work with personnel of the organization, Kompetentnost', Vol.3.

3. Ledwidge, J., (2007), Corporate social responsibility: the risks and opportunities for HR: Integrating human and social values into the strategic and operational fabric, Human Resource Management International Digest, Vol. 15 Issue: 6, pp.27-30.

4. Laszlo, B., (2017), Work rules, Public Publishing House, Bucharest.

5. GUDA, I., (2018), Why do companies fail?, Public Publishing House, Bucharest.

6. KAUFMAN, R.,(2013),Culture of higher services, Public Publishing House, First Edition, Bucharest.

7. KRAMER, S., AMABILE, T., (2013), The principle of progress, Public Publishing House, 1st Edition, Bucharest.

8. Havarneanu, C., Havarneanu, G., (2015), Risk Psychology, Polirom Publishing House,

9. Moller, C., Barlow, J., (2010), Any complaint is a gif, Public Publishing House, First Edition, Bucharest.

10. Ciugudean, V., (2009), Total quality management in rural tourism - Doctoral thesis - University of Agricultural Sciences and Veterinary Medicine Cluj-Napoca, Doctoral School Faculty of Agriculture, Specialization: Management and marketing in agriculture.

11. Armean, A., (2013), Conceptual delimitations between control, management, analysis and risk management in Intercultural Management Volume XV, Nr. 1 (27), pp.15-20, [Article].

12. Ceocea, C., (2010), Risk in management activity, Economic Publishing House, Bucharest, 2010.

13. Isaic-Maniu, I., (2006) Statistical characterization of risk - concepts, techniques, applications, ASE Publishing House, Bucharest.

14. Bărbulescu, C., (2010), High-performance piloting of the enterprise, Economic Publishing House, Bucharest,

15. Lupu F.A., (2009), Risk Management in Romanian Entrepreneurial Organizations in the Context of the Domino of the Economic Crisis, Management Series, Vol.12, [ARTICLE].

16. Armstrong, M., (2006), A Handbook Of Human Resource Management Practice, 10th Edition, Publisher Kogan Page Ltd.

17. Câmpeanu- Sonea, E.,Osoian, C., (2004), Human Resources Management: Recruitment, Selection and Professional Development, Cluj University Press Publishing House, Cluj-Napoca. 
18. David, F., (2008), Strategic management. Concepts and Cases, 11th Edition, New Jersey: Pearson / Prentince Hall.

19. Moraru, R.I., Băbuţ, G.B., (2013), Professional risk assessment: Guide for practical applications and projects, Focus Publishing House, Petroşani, Romania.

20. 26. R.I. Moraru, G.B. Băbuţ, "Participatory risk assessment and management: a practical guide", Universitas Publishing House, Petroşani, Romania, 2010.

21. Rondelli, V., Cojocaru, S., (2004) "Quality management of services in tourism and hospitality industry", THR-CG Publishing House, Bucharest.

22. Chisu, V., (2002), The Handbook of the Human Resources Specialist, Irecson Publishing House, Bucharest.

\section{WEBOGRAPHY}

1. https://www.academia.edu/

2. https://europa.eu/

3. https://insse.ro/cms/

4. https://osha.europa.eu/

5. https://en.wikipedia.org/wiki/Risk 